\title{
A UTILIZAÇÃO DE FERRAMENTAS DE SIMULAÇÃO NUMÉRICA NA OTIMIZAÇÃO DE PROJETOS DE MECANISMOS DE VÁLVULA GAVETA*
}

Lucas Breder Teixeira ${ }^{1}$ Rubens Alves Freire ${ }^{2}$ Fabrício Júnior Silva ${ }^{3}$ Maurício dos Santos ${ }^{4}$

\section{Resumo}

O uso de ferramentas de simulação numérica para análise estrutural vem se expandindo nos últimos anos, sobretudo utilizando o método dos elementos finitos. Nesse trabalho são apresentados dois exemplos de otimização de projetos envolvendo componentes de mecanismos de válvula gaveta, realizados pela Magnesita Refratários S.A. Partindo da geometria inicial até o produto final, é analisado como o campo de tensões é adequado a valores admissíveis, conforme modificações de projeto são realizadas. Por fim, é demonstrada a importância desse tipo de estudo para alcançar maior confiabilidade e segurança em projetos mecânicos.

Palavras-chave: Mecanismo de válvula gaveta; Simulação numérica; Análise estrutural.

\section{THE USE OF NUMERICAL SIMULATION TOOLS IN SLIDE GATE MECHANISMS'S DESIGN OPTIMIZATION}

\begin{abstract}
The use of numerical tools in structural analysis has grown in recent years, specially using the finite elements method. In this work, the design optimization of two slide gate system components are shown, performed by Magnesita Refratários S.A. Starting from the initial geometry until the final product, the adequacy of the stress fields to allowable values is analyzed as design is modified. Finally, the importance of this kind of study to achieve more reliable and safe mechanical design is established. Keywords: Slide gate system; Numerical simulation; Structural analysis.
\end{abstract}

1 Bacharel em Engenharia Mecânica, Engenheiro de Desenvolvimento, Departamento de Engenharia de Soluções, Magnesita Refratários S.A., Contagem, MG, Brasil.

2 Bacharel em Engenharia Mecânica, Coordenador, Projetos Mecânicos e Simulação Numérica, Departamento de Engenharia de Soluções, Magnesita Refratários S.A., Contagem, MG, Brasil.

3 Bacharel em Engenharia Mecânica, Engenheiro de Projetos, Departamento de Engenharia de Soluções, Magnesita Refratários S.A., Contagem, MG, Brasil.

4 Bacharel em Engenharia Mecânica, Especialista de Assistência Técnica, Controle de Fluxo, Departamento de Assistência Técnica, Magnesita Refratários S.A., Contagem, MG, Brasil. 


\section{INTRODUÇÃO}

Ao longo dos últimos anos as técnicas de simulação numérica vêm sendo cada vez mais utilizadas como ferramenta no projeto e análise de componentes mecânicos. A possibilidade de otimizar geometrias complexas para diferentes condições de operação muitas vezes torna essa abordagem viável do ponto de vista econômico, visto que o projeto e fabricação de protótipos pode representar um grande aumento no orçamento.

Nesse trabalho é demonstrado por meio de dois exemplos práticos como a Magnesita Refratários S.A. utiliza ferramentas numéricas na análise estrutural de Mecanismos de Válvula Gaveta (MVG) para controle de fluxo.

O primeiro exemplo trata da redução de tensões na caixa de molas do MVG, que faz parte do conjunto de aperto, mostrado na Figura 1, responsável por fornecer a pressão necessária para as placas durante a operação de forma a evitar vazamentos.

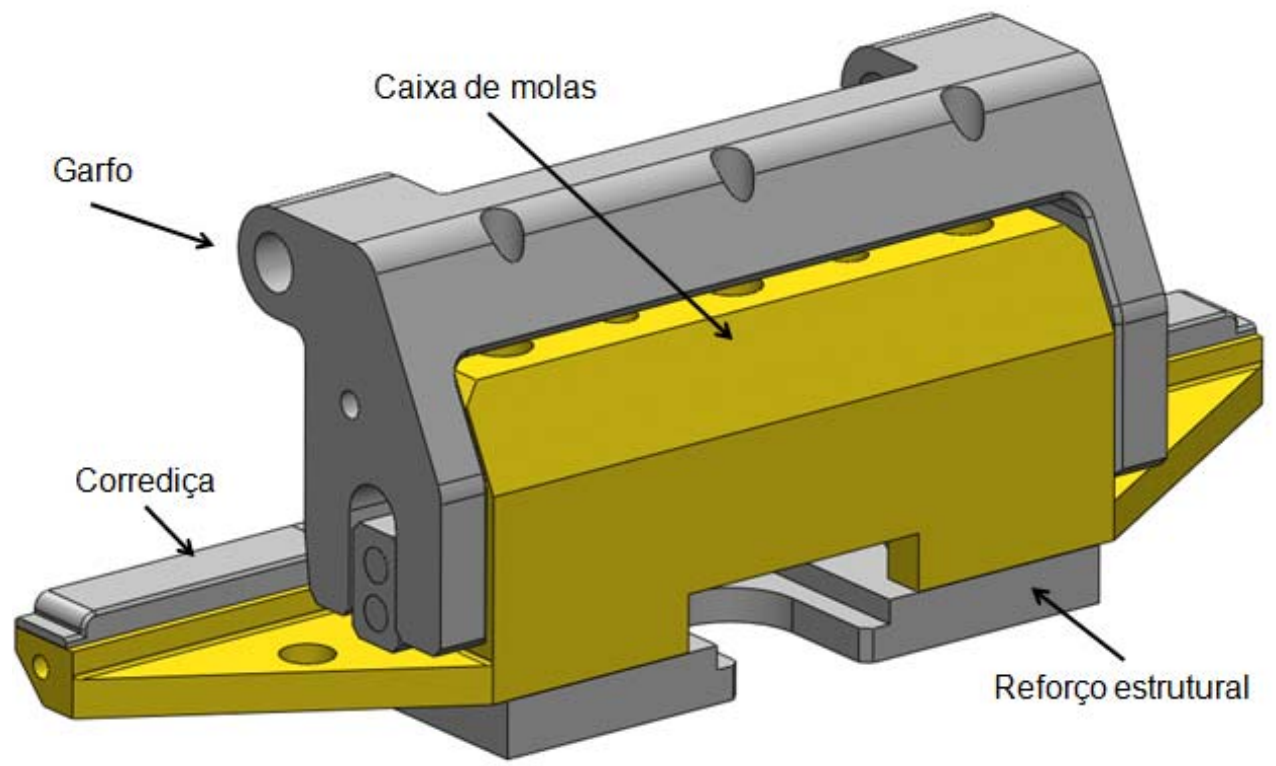

Figura 1. Conjunto de aperto.

O segundo exemplo trata da adequação estrutural do projeto do gancho de acionamento de um mecanismo, onde é acoplado o cilindro hidráulico responsável pelo movimento de abertura e fechamento do sistema.

\section{MÉTODOS}

Para realização dos estudos numéricos foi utilizado o método dos elementos finitos através do software Ansys Mechanical.

Em ambos os casos foi utilizado um modelo de material linear elástico, visto que um dos requisitos do projeto era que não houvesse deformação plástica dos componentes. Tanto a caixa de molas quanto o gancho de acionamento do MVG são fabricados usando o aço fundido SC49, que tem limite de escoamento de aproximadamente $245 \mathrm{MPa}$. Para levar em conta efeitos térmicos e de fadiga, um fator de segurança de 2 foi utilizado, fazendo que a tensão admissível fosse de $122,5 \mathrm{MPa}$.

Abaixo, as condições de contorno impostas em cada um dos casos. 


\subsection{Condições de Contorno - Caixa de Molas}

No primeiro caso, as molas responsáveis por gerar a força de aperto foram retiradas do modelo, e a força foi aplicada diretamente sobre a caixa, conforme mostra a Figura 2. Essa simplificação é necessária para viabilizar os cálculos, e não afeta de forma significativa nos resultados.

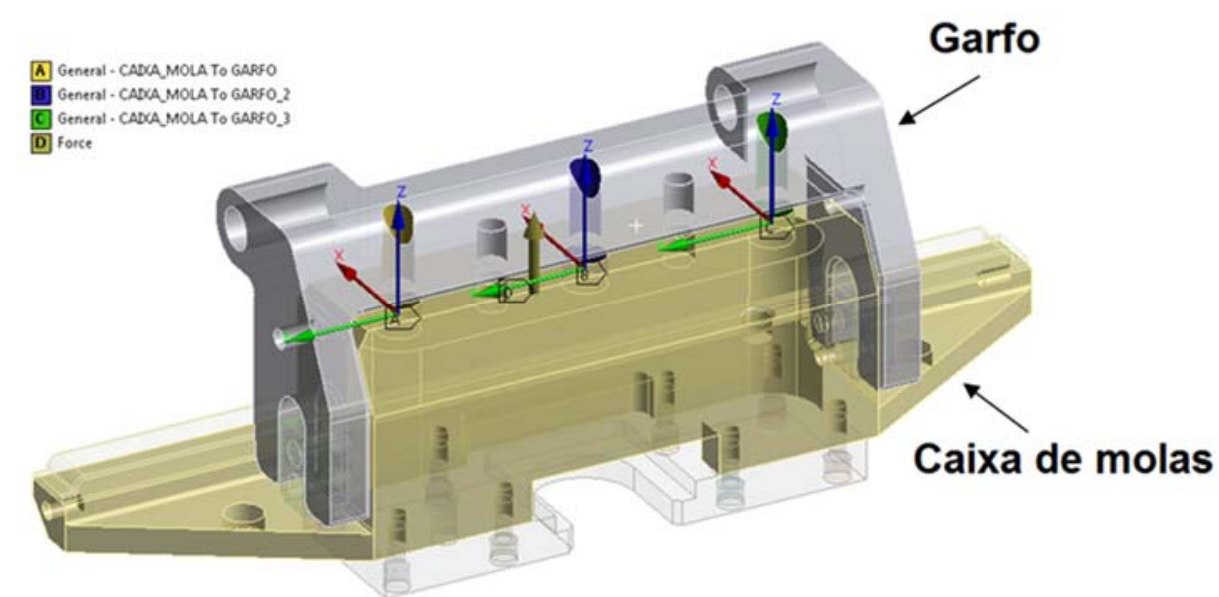

Figura 2. Simplificação do modelo da caixa de molas.

Além disso, a corrediça foi restrita na direção y, e suportes cilíndricos foram aplicados para permitir a rotação do garfo ao redor do eixo $z$, como mostra a Figura 3.

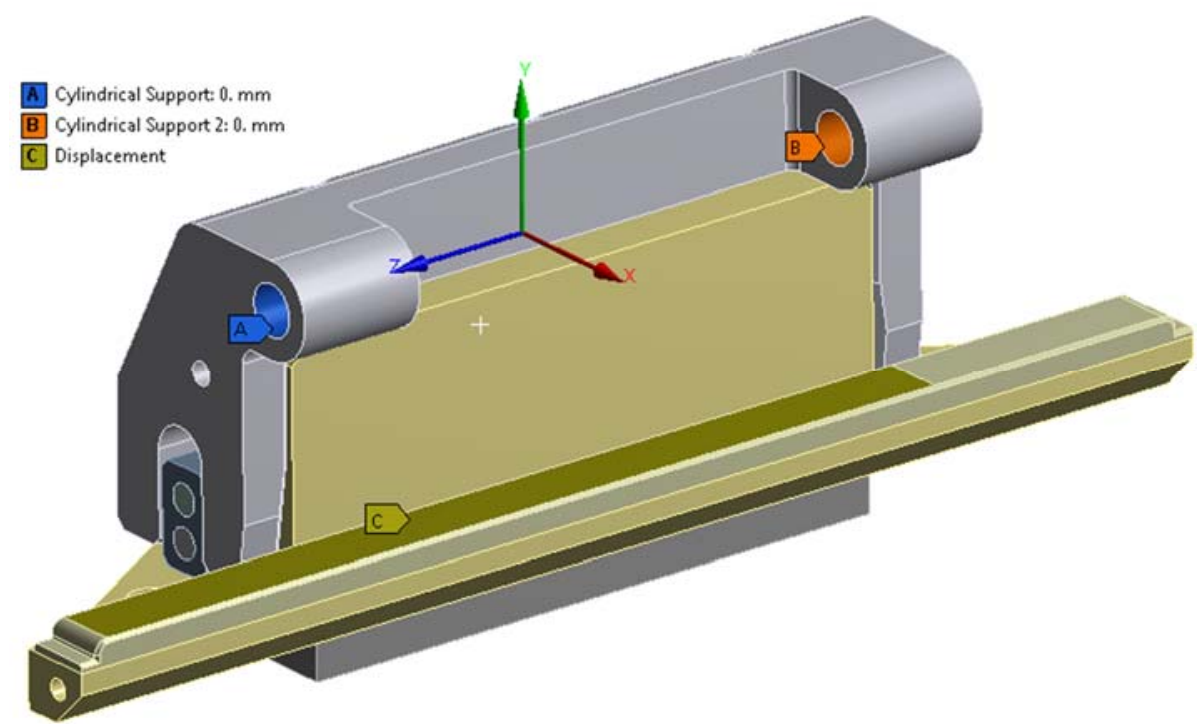

Figura 3. Condições de travamento da caixa de molas.

\subsection{Condições de Contorno - Gancho de Acionamento}

Para o gancho de acionamento foram simuladas duas situações, sendo a abertura e o fechamento do sistema. Para que fosse considerado o cenário de carregamento mais crítico em ambas as situações, o quadro do mecanismo foi considerado travado na direção $z$, e a força máxima do cilindro hidráulico foi aplicada sobre os pinos, conforme mostram a Figura 4 e 5. 


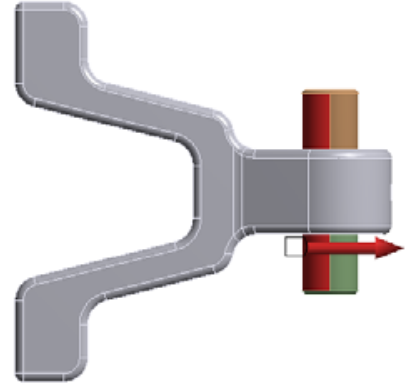

Abertura

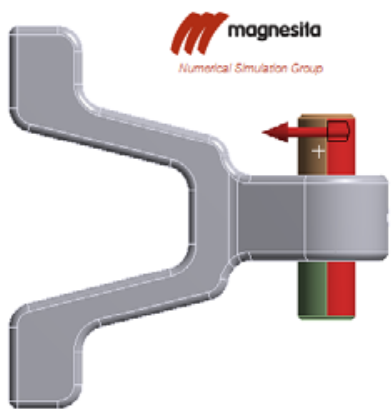

Fechamento

Figura 4. Aplicação da força do cilindro hidráulico sobre os pinos do gancho de acionamento.

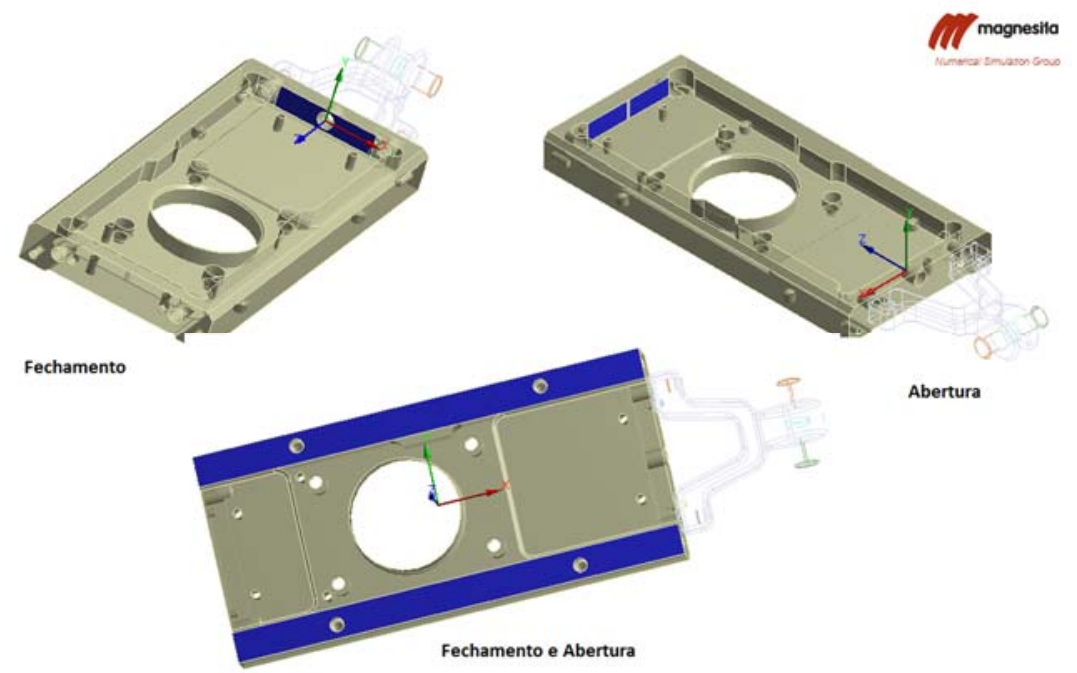

Figura 5. Travamento do quadro na direção $z$.

\section{RESULTADOS E DISCUSSÃO}

A partir das condições de contorno impostas sobre os modelos, foram realizados estudos estruturais e propostas modificações nos projetos, visando diminuir o nível de tensões observado. Tomou-se como base as tensões equivalentes de von Mises, por essas representarem um bom critério de falha para materiais metálicos.

\subsection{Análise das Tensões Equivalentes - Caixa de Molas}

Inicialmente foi simulada a geometria original da caixa de molas, para detectar pontos de concentração de tensões e propor melhorias, como mostrado a seguir.

\subsubsection{Geometria original}

A Figura 6 mostra o campo de tensões obtido para a geometria inicial. Como é possível observar, as tensões equivalentes chegaram a aproximadamente $158 \mathrm{MPa}$ na região de maior concentração, o que indica uma possibilidade de plastificação do material. Uma análise mais cuidadosa da geometria mostrou que nessa região havia a presença de um furo para utilização de um parafuso de fixação do reforço estrutural da caixa de molas, um furo para fixação da corrediça na caixa de molas através de um pino, e que o raio da peça nessa mesma região era bastante agudo, conforme mostra a Figura 7. 
Unit MP?
Time: 1
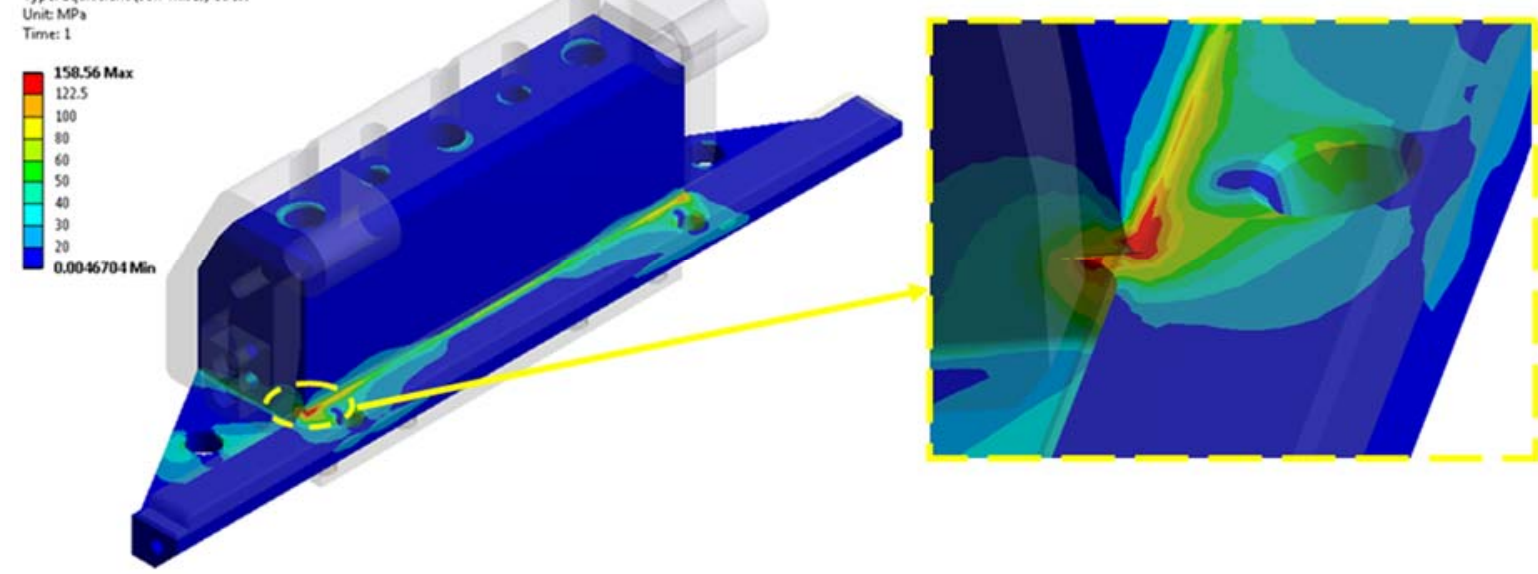

Figura 6. Concentração de tensões na caixa de molas.

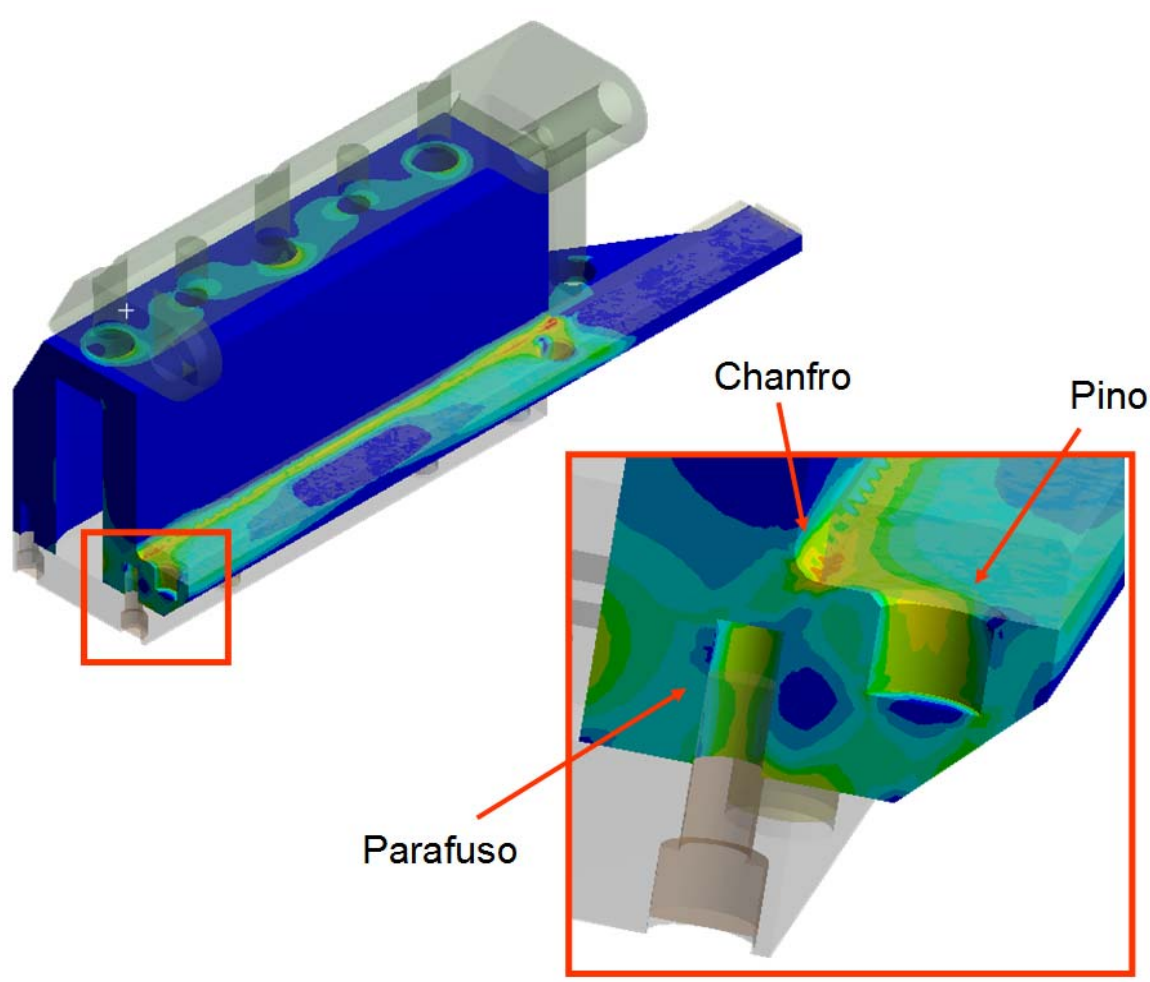

Figura 7. Concentração de tensões na caixa de molas - vista em corte e em detalhe.

\subsubsection{Modificação 1 - Mudança da posição do pino da corrediça e suavização do raio no concentrador de tensões}

Para reduzir o nível de tensões na região mais crítica da caixa de molas, foi proposto o deslocamento do furo de fixação da corrediça e a suavização do raio, como mostrado na Figura 8. Com isso, a tensão equivalente máxima se reduziu a 135 $\mathrm{MPa}$, além de diminuir a área sujeita a tensões acima de $122,5 \mathrm{MPa}$, como mostrado na Figura 9. No entanto, as tensões ainda não haviam ficado abaixo do valor admissível, e foi realizada mais uma modificação para alcançar esse fim. 


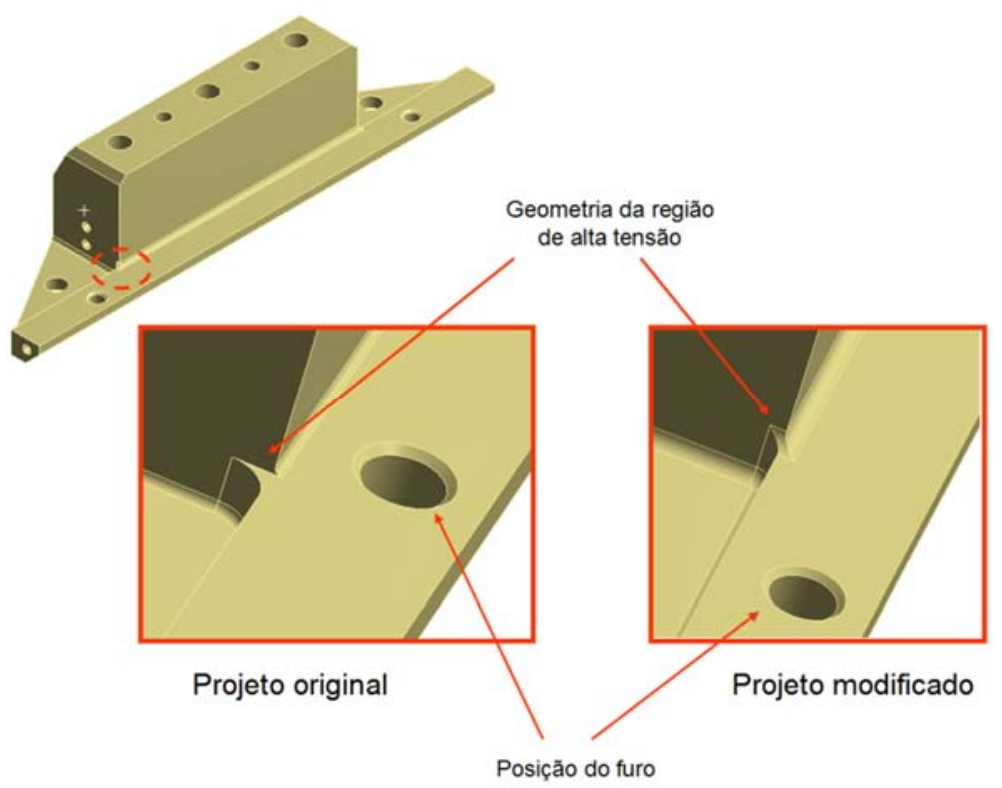

Figura 8. Modificações propostas na geometria da caixa de molas.

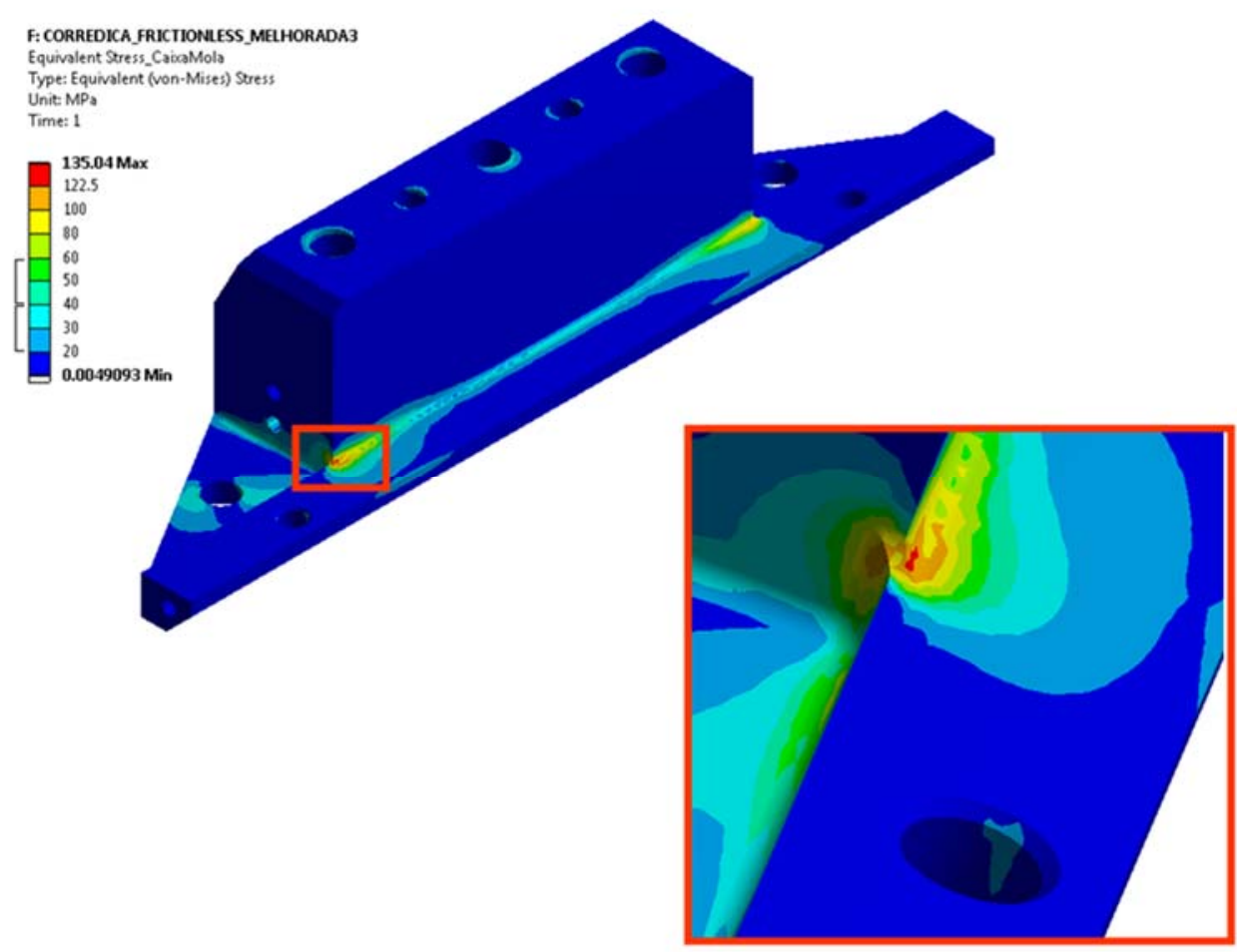

Figura 9. Tensões equivalentes na primeira geometria modificada da caixa de molas.

\subsubsection{Modificação 2 - Aumento da espessura da base da caixa de molas}

Para aumentar a área resistente aos esforços e, consequentemente, diminuir as tensões no componente, a espessura da base da caixa de molas foi aumentada de $20 \mathrm{~mm}$ para $25 \mathrm{~mm}$, conforme a Figura 10. Com isso, a tensão equivalente máxima calculada foi de $113,53 \mathrm{MPa}$, ficando abaixo da tensão admissível definida como critério de projeto, como mostrado na Figura 11. 


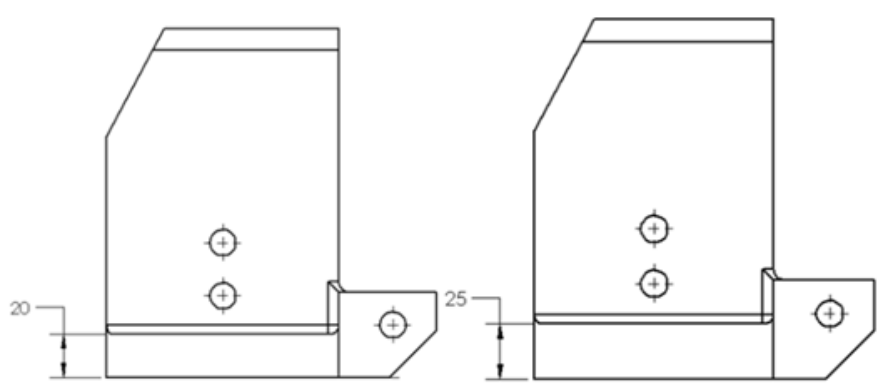

Figura 10. Aumento da espessura da base da caixa de molas.

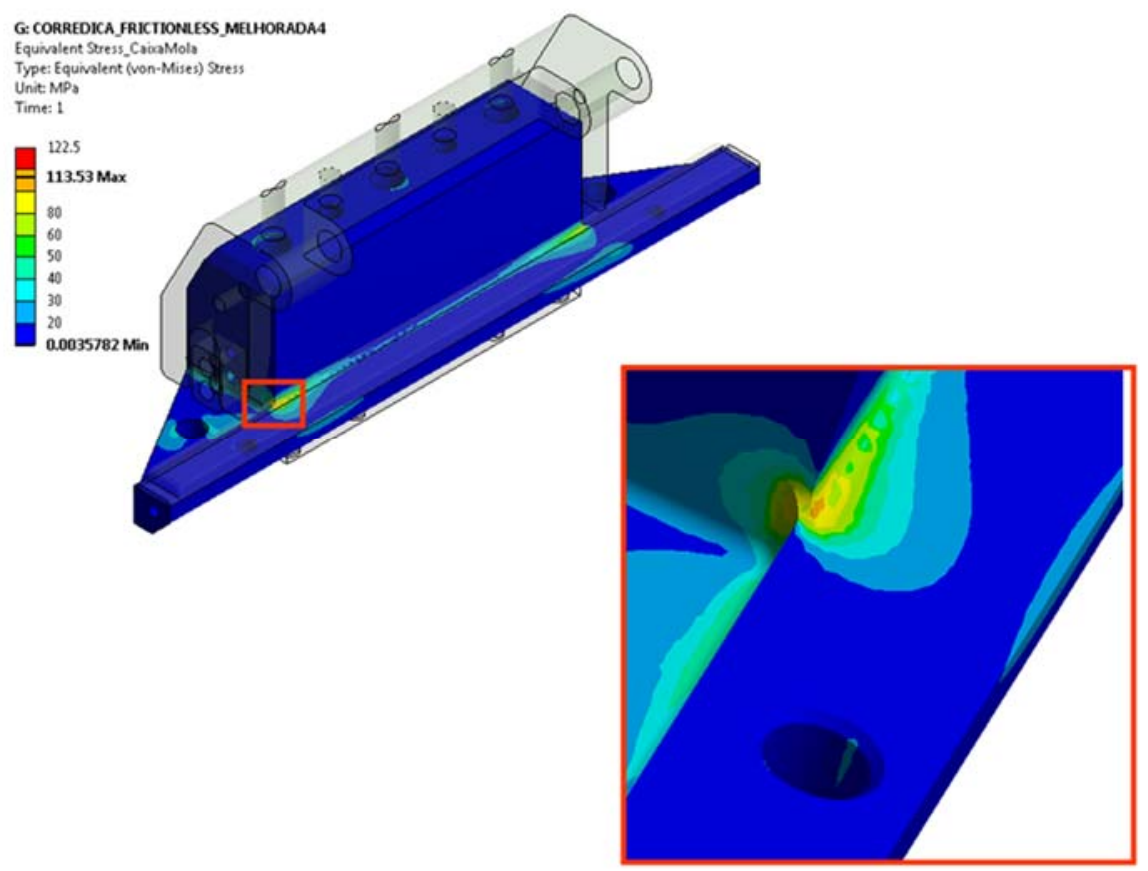

Figura 11. Tensões equivalentes na segunda geometria modificada da caixa de molas.

\subsection{Análise das Tensões Equivalentes - Gancho de Acionamento}

Para a análise do gancho de acionamento foi seguida a mesma metodologia utilizada para a caixa de molas, ou seja, o projeto original foi simulado e foram propostas modificações até que se alcançasse um nível de tensões aceitável. $O$ caso mais crítico para esse componente corresponde ao movimento que tende a tracioná-lo, obtido durante a abertura do sistema, e os resultados calculados para essa situação são mostrados abaixo.

\subsubsection{Geometria original}

A Figura 12 mostra as tensões equivalentes calculadas para a geometria original do gancho de acionamento. Como é possível observar, uma extensa área da peça está sofrendo tensões acima da máxima admissível, e por isso foi proposta uma grande modificação no projeto desse componente. 


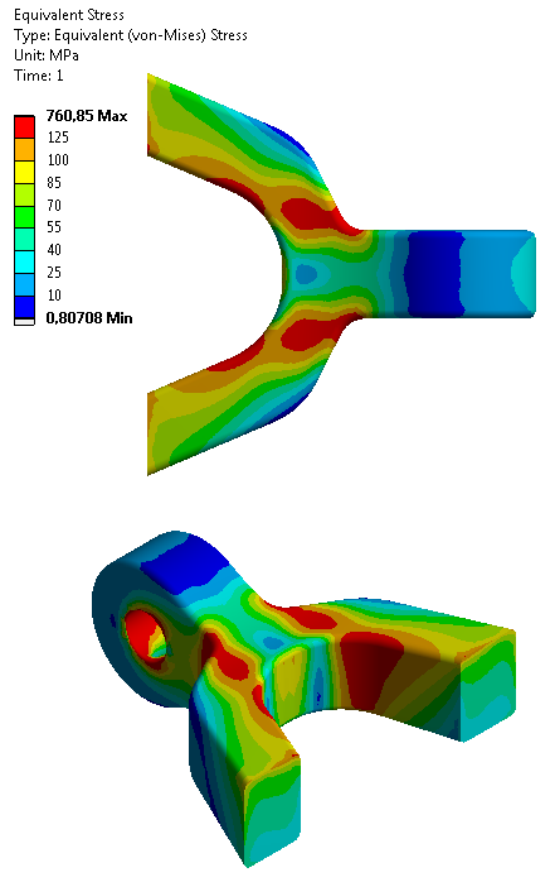

Figura 12. Tensões equivalentes na geometria original do gancho de acionamento.

\subsubsection{Geometria modificada}

Após a realização de diversas simulações e a suavização da geometria da peça, foi obtido um campo de tensões bastante inferior ao da geometria original, como mostrado na Figura 13. Dessa forma, o projeto teve seu fator de segurança aumentado. Percebe-se também que na região do furo onde é colocado o pino para aplicação da força ainda existe uma tensão equivalente alta, mas que não apresenta preocupação por não ser uma região crítica para o aparecimento e propagação de trincas.

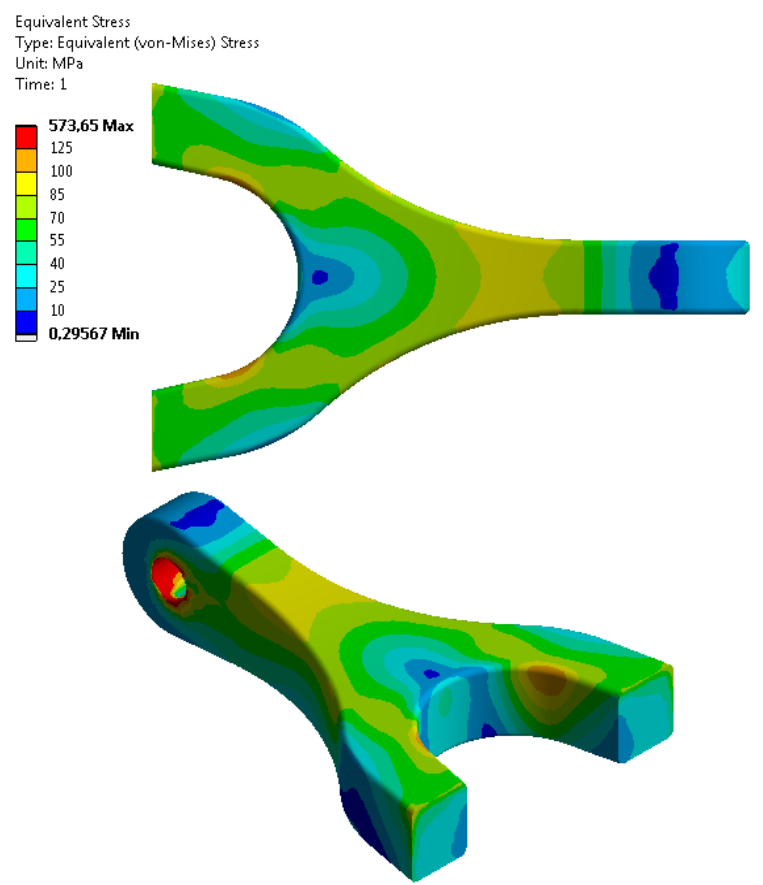

Figura 13. Tensões equivalentes na geometria modificada do gancho de acionamento. 


\section{CONCLUSÃO}

Nesse trabalho foi apresentada a maneira como a Magnesita Refratários S.A. utiliza ferramentas de simulação numérica para otimização estrutural do projeto de Mecanismos de Válvula Gaveta, buscando da melhor maneira possível aumentar a segurança e confiabilidade desse componente.

Seguindo essa metodologia, foram realizados estudos que diminuíram consideravelmente o nível de tensões na caixa de molas e no gancho de acionamento de mecanismos, fazendo com que eles trabalhassem abaixo da tensão admissível definida pela equipe de projetos.

Deve-se destacar que esse tipo de trabalho é também realizado para análise e projeto de outros componentes mecânicos que fazem parte do portfólio da Magnesita, e também para estudo de montagens refratárias e equipamentos de clientes. 